\title{
Effectiveness of UV Disinfection for Contaminated Surface Water
}

\author{
Priyanka Ali, Mohammad Fahad Bin Alam, and Muhammad Ashraf Ali
}

\begin{abstract}
In Bangladesh, surface water (e.g., pond/river water) and rainwater are important sources of potable water, particularly in areas suffering from arsenic contamination of groundwater and high salinity. However, surface water often suffers from high microbial contamination and needs disinfection for potable use. Disinfection is a challenge for small water supply systems, as a family or small communities often do not have necessary facilities to disinfect water properly. Many commercially available household-level treatment systems are not effective in removing pathogens. This study presents an assessment of the effectiveness of UV disinfection for highly contaminated surface water. Disinfection experiments were carried out in a large $(152 \mathrm{~cm} \times 48 \mathrm{~cm} \times 48 \mathrm{~cm})$ container under different operational (e.g., UV lamp intensity, exposure time) and water quality (e.g., initial FC, turbidity) conditions. UV disinfection could significantly reduce microbial (FC) contamination from highly polluted surface water with initial FC concentration varying from 8,000 to $24,000 \mathrm{cfu} / 100 \mathrm{ml}$. The effectiveness of $\mathrm{UV}$ disinfection has been found to depend on a number of operational factors including intensity of lamp, exposure time, and distance from the lamp. Although FC concentration could not be reduced to zero (which is the national drinking water standard) under the experimental condition used in this study, the results suggest that this could be achieved with appropriate combination of lamp intensity, exposure time and tank dimension. Thus, UV disinfection could potentially be used for treatment of surface (pond/river) water in water scarce areas (e.g., arsenic-affected or salinity-prone areas).
\end{abstract}

Index Terms-Disinfection efficiency, fecal coliform, lamp intensity, UV disinfection.

\section{INTRODUCTION}

Bangladesh has made significant progress in improving water supply coverage in the past decades [1]. Ground water is the major sources of water supply throughout the country, primarily through use of shallow and deep tubewells; besides, surface water sources and rain water harvesting systems (RWHS) are important sources for water. Presence of elevated levels of arsenic (As) in groundwater in many parts of the country [2]-[4] has forced people to choose surface water sources or RWHS for drinking purpose, especially in areas where suitable As-free deep aquifers are not available. On a national scale, 25.5 percent of water sources have As concentration exceeding the WHO guideline value of $10 \mathrm{ppb}$, and 12.5 percent have As exceeding national standard of 50 ppb [3]. People in the salinity-affected southern coastal areas

Manuscript received April 30, 2016; revised July 20, 2016.

Priyanka Ali, Mohammad Fahad Bin Alam, and Muhammad Ashraf Ali are with the Department of Civil Engineering, Bangladesh University of Engineering and Technology (BUET), Dhaka 1000, Bangladesh (e-mail: ashraf@ce.buet.ac.bd, mashrafali88@gmail.com). of Bangladesh are dependent on RWHS (during wet season) and pond water for potable water supply. Water from surface water sources (e.g. ponds, lakes, rivers etc.) is often used for drinking purpose through use of pond sand filters (PSF); however, such systems have not been very successful due to problems related to operation and maintenance [5], [6]. PSF and RWHS together account for $6.7 \%, 5.9 \%$, and $9.1 \%$ of water supply points, respectively in Khulna, Satkhira and Bagerhat, the major coastal districts suffering from both high salinity and As contamination [7]. The main problem related to use of ponds and rivers for potable water supply is widespread fecal/microbial contamination of these water sources [6], primarily due to drainage of polluted water from nearby on-site sanitation facilities, discharge of domestic wastewater/ sullage, and use of water bodies for multiple purposes (e.g., bathing, washing, etc.). An effective and low-cost disinfection system that could be implemented in rural areas, often without grid power supply, could significantly improve access to safe potable water in many areas of Bangladesh.

Disinfection is carried out for inactivation/destruction of pathogenic organisms to prevent spread of waterborne diseases. Various disinfection methods include Chlorination, Ozonation, Boiling, Ultraviolet (UV) radiation and a combination of UV and Ozonation. Interest in UV disinfection is growing due to its ability to inactivate pathogenic microorganisms without forming regulated disinfection byproducts (DBPs) [8], [9]. UV light has proven effective against Cryptosporidium, which is resistant to commonly used disinfectants like chlorine. Worldwide many UV disinfection facilities are treating drinking water [10].

For small water supply systems (e.g., pond/ river water, rainwater harvesting), disinfection becomes a challenge since a single family or small communities do not have necessary facilities to disinfect water properly. Even many existing piped water supply systems in urban areas cannot ensure pure drinking water, primarily due to contamination within distribution network. This situation demands treatment facilities at family/community level to ensure safe drinking water. Recent research works suggests that many commercially available household-level treatment systems are not very effective in removing coliform bacteria (FC) [11]. A number of studies suggest that UV disinfection could be effective for disinfection of water in household level rainwater harvesting systems [12]-[15]. Recent studies [6]-[11] have demonstrated that UV treatment in small containers could be very effective for disinfection of moderately contaminated water (e.g. in RWHS). Such UV systems, which could run on solar power, could also be very effective for disinfection of contaminated surface water at 
household or community level. The performance of UV disinfection is likely to depend on a number of factors, e.g., intensity of UV lamp, exposure time, characteristics of water (e.g., level of bacterial contamination, turbidity), and shape/size of container/chamber used for disinfection. It is therefore very important to systematically assess the performance of UV disinfection to treat contaminated surface water under various operational and water quality conditions. This study presents an assessment of the effectiveness of UV disinfection for treatment of highly contaminated surface water under different conditions.

\section{MethodolOGY}

The experiments for UV disinfection have been carried out in a large acrylic glass tank, $152 \mathrm{~cm}$ in length, $48 \mathrm{~cm}$ width and $48 \mathrm{~cm}$ in height. The capacity of the tank is about 355 liters. The tank was fitted with a port for UV lamp at one end, and four sampling ports $30.5 \mathrm{~cm}$ away from each other (see Fig. 1). UV lamps of $6 \mathrm{~W}$ to $16 \mathrm{~W}$ intensities were employed in this study.

Water from a pond that receive domestic sewage discharge, and amended water (e.g., groundwater amended with polluted water containing microorganisms) were used as raw water in the disinfection experiments. For each set of experiment, the raw water was analyzed for a range of parameters including fecal coliform (FC) and Turbidity. Initial FC was varied (by dilution with groundwater) in the disinfection experiments in order to assess its impact on disinfection.

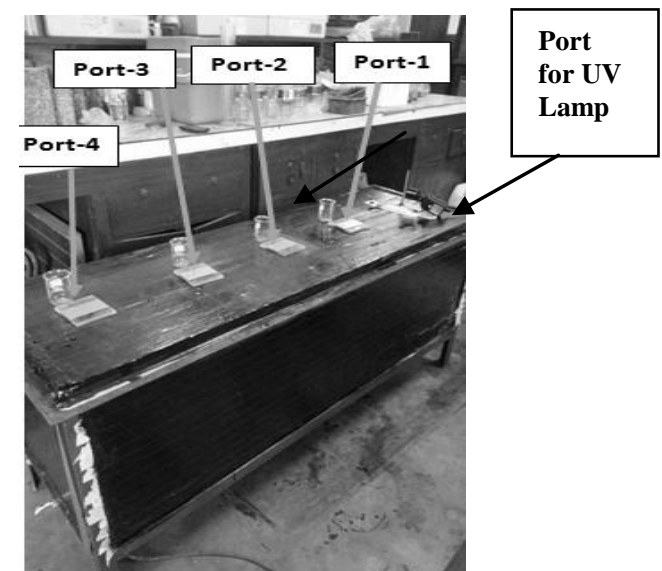

Fig. 1. Experimenal set up for UV disinfection experiment.

For a particular set of experiment, the water tank was filled with the water sample to be disinfected, and then a UV lamp (either $6 \mathrm{~W}$ or $16 \mathrm{~W}$ ) was inserted vertically at the lamp port. Before turning on the UV lamp, water samples were collected from the sampling ports to measure concentrations of selected parameters ( $\mathrm{pH}$, Color, Turbidity, and FC). The UV lamp was then turned on and water samples were collected from the four sampling ports after fixed intervals of 10, 20 and 40 minutes. The water samples were tested for fecal coliform (FC) to assess the effect of disinfection. Similar experiments were carried out by varying lamp intensity, exposure time and raw water quality (initial FC concentration, Turbidity). Results of the disinfection experiments were analyzed to assess: (i) effect of lamp intensity and exposure time on disinfection; (ii) effect of distance from lamp on disinfection, and (ii) effect of water quality (FC concentration and turbidity) on disinfection. Membrane filtration technique was used for determination of FC; Standard Methods was used for determination of other parameters.

\section{RESULT AND DISCUSSION}

\section{A. Effects of UV Lamp Intensity on Disinfection}

In order to evaluate the effects of UV lamp intensity on disinfection efficiency, a number of experiments were carried out with $6 \mathrm{~W}$ and 16W UV lamps. Table I and Table II show the residual FC concentration and disinfection efficiency for water samples collected from Port 1 and Port 4, respectively at different exposure times. It should be noted that among the sampling ports identified, Port 1 receives the highest UV intensity, while Port 4 receives the least; thus these two ports are of highest interest. The figures and tables show that disinfection efficiency depends on UV lamp intensity, and higher intensity UV lamp could achieve higher removal efficiency.

TABLE I: RESIDUAL FC CONCENTRATION AND DISINFECTION EFFICIENCY FOR WATER SAMPLES COLLECTED AT DIFFERENT EXPOSURE TIMES FROM PORT 1 OF WATER TANK FITTED WITH 6W AND 16W UV LAMP

\begin{tabular}{lcccc}
\hline \multirow{2}{*}{$\begin{array}{c}\text { Exposure } \\
\text { Time }\end{array}$} & \multicolumn{2}{c}{ FC $(\mathrm{cfu} / 100 \mathrm{~mL})$} & \multicolumn{2}{c}{ Disinfection Efficiency $(\%)$} \\
\cline { 2 - 5 } & $6 \mathrm{~W}$ & $16 \mathrm{~W}$ & $6 \mathrm{~W}$ & $16 \mathrm{~W}$ \\
\hline Raw/0 Min & 24000 & 8000 & -- & -- \\
\hline $10 \mathrm{Min}$ & 600 & 50 & 97.5 & 99.4 \\
\hline $20 \mathrm{Min}$ & 500 & 30 & 97.9 & 99.6 \\
\hline $30 \mathrm{Min}$ & 320 & 22 & 98.7 & 99.7 \\
\hline $40 \mathrm{Min}$ & 120 & 12 & 99.5 & 99.9 \\
\hline
\end{tabular}

TABLE II: RESIDUAL FC CONCENTRATION AND DISINFECTION EFFICIENCY FOR WATER SAMPLES COLLECTED AT DIFFERENT EXPOSURE TIMES FROM PORT 4 OF WATER TANK FITTED WITH 6W AND 16W UV LAMP

\begin{tabular}{lcccc}
\hline \multirow{2}{*}{$\begin{array}{c}\text { Exposure } \\
\text { Time }\end{array}$} & \multicolumn{2}{c}{ FC $(\mathrm{cfu} / 100 \mathrm{~mL})$} & \multicolumn{2}{c}{ Disinfection Efficiency (\%) } \\
\cline { 2 - 5 } & $6 \mathrm{~W}$ & $16 \mathrm{~W}$ & $6 \mathrm{~W}$ & $16 \mathrm{~W}$ \\
\hline Raw/0 Min & 24000 & 8000 & -- & -- \\
\hline $10 \mathrm{Min}$ & 1760 & 300 & 92.7 & 96.3 \\
\hline $20 \mathrm{Min}$ & 1280 & 270 & 94.7 & 96.6 \\
\hline $30 \mathrm{Min}$ & 450 & 185 & 98.1 & 97.7 \\
\hline $40 \mathrm{Min}$ & 350 & 84 & 98.5 & 99.0 \\
\hline
\end{tabular}

\section{B. Effect of Exposure Time}

Higher exposure to UV radiation would yield higher disinfection efficiency. However, higher exposure means higher power consumption and lower lamp-life, and therefore it is important to estimate the optimum exposure time for a particular condition of UV irradiation and water quality [16], [17]. Table III and Table IV show that exposure time has a clear effect on disinfection efficiency; higher the exposure time, the better is the disinfection efficiency (Figs. 2 and 3). For example, at Port 2, residual FC concentration decreased to $250 \mathrm{cfu} / 100 \mathrm{ml}$ after 10 minutes of exposure, while it reached $20 \mathrm{cfu} / 100 \mathrm{ml}$ after 40 minutes of exposure. However, as discussed earlier, the effect of exposure time is also a strong function of the position of the sampling port with respect to the lamp; Port 1 would require less exposure time of UV radiation compared to Port 4 for achieving the same disinfection efficiency. For example after 20 minutes of exposure time, residual $\mathrm{FC}$ was $30 \mathrm{cfu} / 100 \mathrm{~mL}$ at Port 1 
(located $30.5 \mathrm{~cm}$ away from the lamp), while it was 350 $\mathrm{cfu} / 100 \mathrm{ml}$ at Port 4 (located $122 \mathrm{~cm}$ away from the lamp).

\section{Effect of Distance from UV Lamp}

As discussed earlier in Section II, the horizontal distance of sampling Ports 1, 2, 3 and 4 from the UV lamp are $30.5 \mathrm{~cm}, 61$ $\mathrm{cm}, 91.5 \mathrm{~cm}$, and $122 \mathrm{~cm}$, respectively. Fig. 4 shows the residual FC concentration of water samples collected from four different ports after 10 and 40 minutes of exposure times, for water sample with initial FC concentration of 8000 $\mathrm{cfu} / 100 \mathrm{ml}$. It shows very significant effect of distance (from UV lamp) on disinfection; disinfection efficiency decreases rapidly as distance increases. In all cases, samples collected from Port 1 exhibited lowest FC, while those collected from Port 4 showed highest FC concentration.

TABLE III: RESIDUAL FC CONCENTRATION OF WATER SAMPLES (INITIAL FC: 8000 CFU/100ML) COLLECTED AT DIFFERENT EXPOSURE TIME FROM THE WATER TANK FITTED WITH 16W UV LAMP

\begin{tabular}{ccccc}
\hline Time of Exposure & \multicolumn{4}{c}{ Residual FC $(\mathrm{cfu} / 100 \mathrm{~mL})$} \\
\cline { 2 - 5 } & Port 1 & Port 2 & Port 3 & Port 4 \\
\hline Raw/0 Min & 8000 & 8000 & 8000 & 8000 \\
\hline 10 Min & 50 & 250 & 300 & 420 \\
\hline 20 Min & 30 & 160 & 270 & 350 \\
\hline 30 Min & 22 & 120 & 155 & 200 \\
\hline 40 Min & 12 & 20 & 84 & 96 \\
\hline
\end{tabular}

TABLE IV: RESIDUAL FC CONCENTRATION OF WATER SAMPLES (INITIAL FC: 9000 CFU/100ML) COLLECTED AT DIFFERENT EXPOSURE TIME FROM THE WATER TANK FITTED WITH 16W UV LAMP

\begin{tabular}{ccccc}
\hline Time of Exposure & \multicolumn{4}{c}{ Residual FC $(\mathrm{cfu} / 100 \mathrm{~mL})$} \\
\cline { 2 - 5 } & Port 1 & Port 2 & Port 3 & Port 4 \\
\hline Raw/0 Min & 9000 & 9000 & 9000 & 9000 \\
\hline 10 Min & 230 & 400 & 460 & 840 \\
\hline 20 Min & 150 & 280 & 350 & 450 \\
\hline 30 Min & 56 & 150 & 180 & 230 \\
\hline 40 Min & 16 & 60 & 85 & 120 \\
\hline
\end{tabular}

ALL PORT (EFFICIENCY)

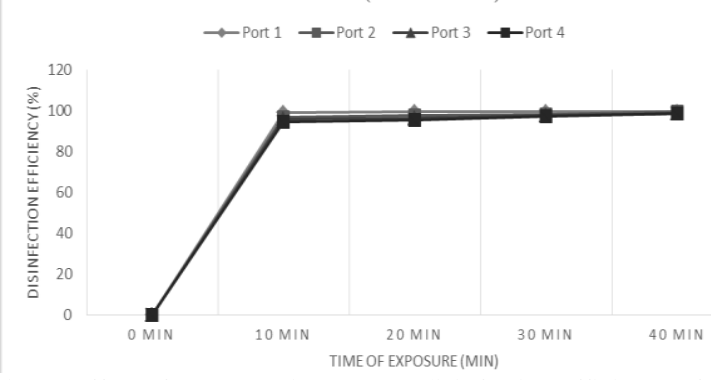

Fig. 2. Effect of exposure time on UV disinfection efficiency of water samples (Initial FC: $8000 \mathrm{cfu} / 100 \mathrm{~mL}$ ) for experiment carried out with $16 \mathrm{~W}$ UV lamp.

\section{Effects of Initial FC Concentration and Turbidity}

Data presented in Table III and Table IV show the effect of initial FC concentration on disinfection efficiency. For example, from an initial concentration of $8000 \mathrm{cfu} / 100 \mathrm{ml}, \mathrm{FC}$ concentration was reduced to $50 \mathrm{cfu} / 100 \mathrm{ml}$ in Port 1 in 10 minutes; whereas for an initial FC concentration of 9000 $\mathrm{cfu} / 100 \mathrm{ml}$, the corresponding value is $230 \mathrm{cfu} / 100 \mathrm{ml}$. Thus, higher initial FC concentration would reduce disinfection efficiency significantly. The initial turbidity of water samples used for the disinfection experiments varied from 4.76 to 8.4 NTU. No significant effect of turbidity on disinfection was apparent within this narrow range of turbidity.

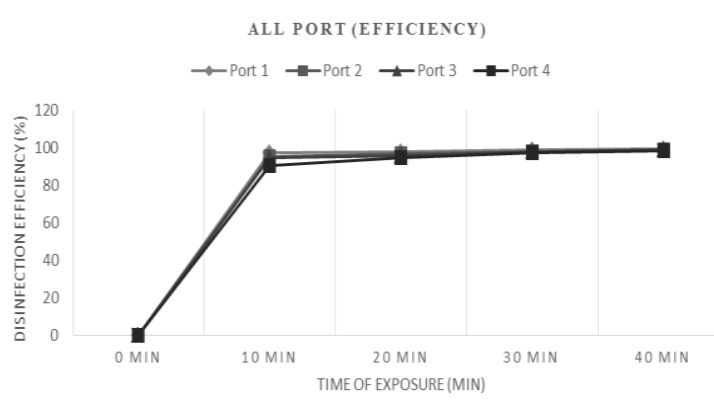

Fig. 3. Effect of exposure time on UV disinfection efficiency of water samples (Initial FC: $9000 \mathrm{cfu} / 100 \mathrm{~mL}$ ) for experiment carried out with $16 \mathrm{~W}$ UV lamp.

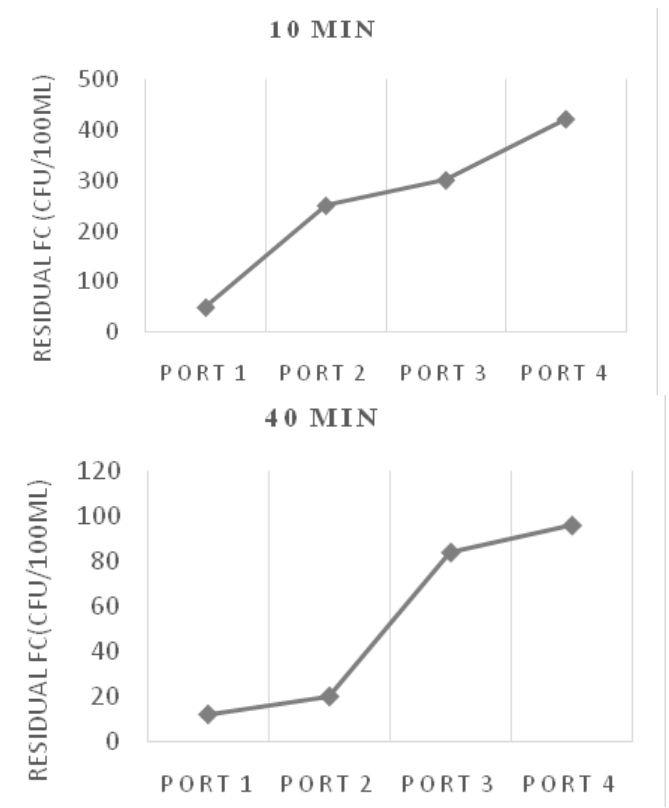

Fig. 4. Residual FC of water samples at different sampling ports at different exposure times for experiments carried with water having initial FC of 8000 cfu/100 ml and 16W UV lamp.

\section{CONCLUSIONS AND RECOMMENDATIONS}

UV disinfection carried out in large water tank could significantly reduce microbial (FC) contamination from highly polluted surface water (with initial FC concentration varying from 8,000 to $24,000 \mathrm{cfu} / 100 \mathrm{ml}$ ). The effectiveness of UV disinfection carried out in a tank/container depends on a number of operational factors including intensity of lamp, exposure time, and distance from the lamp. UV disinfection efficiency decreases with increasing distance of the sample collection point from the UV lamp. Although FC concentration of contaminated water could not be reduced to the national drinking water standard of "zero" under the experimental condition employed in this study, the results suggest that this could be achieved with proper combination of lamp intensity, exposure time and tank dimension. Thus, solar powered UV disinfection could potentially be used for treatment of contaminated surface (pond/river) water in water-scarce areas (e.g., arsenic-affected or salinity-prone areas). More studies are needed to optimize the operational parameters (e.g., tank size, number and intensity of lamp(s) for a particular tank size) considering water quality (e.g., initial FC, turbidity) for ensuring effective disinfection of contaminated water with UV radiation. 


\section{REFERENCES}

[1] Unicef and WHO, "Progress on sanitation and drinking water - 2015 update and MDG assessment," 2015.

[2] BGS and DPHE, "Arsenic contamination of groundwater in Bangladesh,” British Geological Survey (BGS) and Department of Public Health Engineering (DPHE), 2001.

[3] BBS and Unicef, "Multiple indicator cluster survey, 2012-2013, progotir pahey," Bangladesh Bureau of Statics (BBS) and Unicef, 2015.

[4] S. J. Hug, D. Gaertner, L.C. Roberts, M. Schirmer, T. Ruettimann, T. M. Rosenberg, A. B. M. Badruzzaman, and M. A. Ali, “Avoiding high concentrations of arsenic, manganese and salinity in deep tubewells in Munshiganj district," Applied Geochemistry, vol. 26, no. 7, pp. 1077-1085, 2011.

[5] M. A. Ali, "Arsenic contamination of groundwater in Bangladesh," International Reviews for Environmental Strategies, vol. 6, no. 2, pp. 329-360, 2006.

[6] ITN-BUET, "Project completion report: Alternative options for access to safe water in coastal areas, funded by UKAID and CAFOD,' International Training Network Centre of Bangladesh University of Engineering and Technology (ITN-BUET) during 2013-2015, May 2015.

[7] DPHE, "National MIS for WSS in Bangladesh, Policy Support Unit (PSU), local government division, Ministry of Local Government, rural development and cooperatives," Government of Bangladesh, 2012.

[8] G. Bitton, Wastewater Microbiology, John Wiley \& Sons, 2005.

[9] R. L. Wolfe, "Ultraviolet disinfection of potable water," Environmental Science \& Technology, vol. 24, no. 6, pp. 768-773,1990.

[10] USEPA, "Design ultraviolet disinfection guidance manual for the final long term 2 enhanced surface water treatment rule," Office of Water (4601), EPA 815-R-06-007, 2006.

[11] K. U. Sikder, "Ultraviolet disinfection for small water supply systems," M.S. thesis, Department of Civil Engineering, Bangladesh University of Engineering and Technology (BUET), Dhaka, Bangladesh, 2015.

[12] JWRC, "Overview of UV disinfection," Japan Water Research Center (JWRC), Keiichi Hara, 2013.

[13] W. Pronk et al., "Decentralized systems for potable water and the potential of membrane technology," Water Research, vol. 43, no. 2, pp 245-265, 2009.

[14] A. Gadgil, "Drinking water in developing countries," Annual Review of Energy and the Environment, vol. 23, no. 1, pp. 253-286, 1998.

[15] Z. Li et al., "Rainwater harvesting and greywater treatment systems for domestic application in Ireland," Desalination, vol. 260, no. 1, pp. 1-8, 2010 .
[16] T. K. Das, "Ultraviolet disinfection application to a wastewater treatment plant," Clean Products and Processes, vol. 3, no. 2, pp. 69-80, 2001.

[17] J. L. Zimmer and R. M. Slawson, "Potential repair of Escherichia coli DNA following exposure to UV radiation from both medium-and low-pressure UV sources used in drinking water treatment," Applied and Environmental Microbiology, vol. 68, no. 7, pp. 3293-3299, 2002.

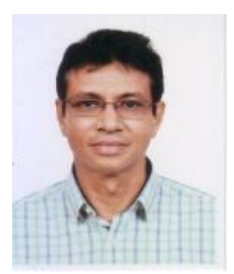

Muhammad Ashraf Ali was born in Kushtia Bangladesh in 1965. He completed his B.Sc. degree in civil engineering from Bangladesh University of Engineering and Technology (BUET), Dhaka Bangladesh in 1988. He then completed his M.Sc. and Ph.D. in civil and environmental engineering from Carnegie Mellon University, Pittsburgh, Pennsylvania, USA in 1991, and 1994, respectively.

He has been working as a faculty member in the Department of Civil Engineering at BUET since 1995. He is currently working as a professor in the Department. He has over 100 publications, including 47 publications in reputed journals, including Science, Nature Geoscience, and ES\&T. H

Professor Ali is a life fellow of the Institution of Engineers, Bangladesh (IEB). He is currently serving as the director of International Training Network (ITN) Center of BUET.

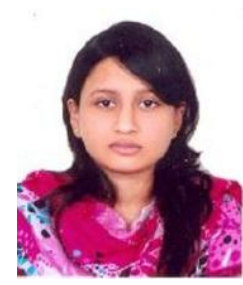

Priyanka Ali was born in Dhaka, Bangladesh in 1991. She has obtained a bachelor of science degree in civil engineering, majoring in environmental engineering from Faculty of Civil Engineering, Bangladesh University of Engineering and Technology (BUET) in 2016. She is currently pursuing her M.Sc. degree in civil and environmental engineering at BUET.

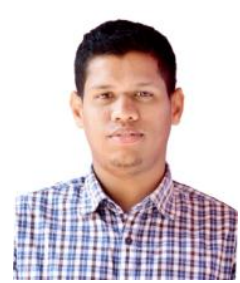

Mohammad Fahad Bin Alam was born in Chittagong, Banglaesh in 1992. He completed his B.Sc. degree in civil engineering from Bangladesh University of Engineering and Technology (BUET), Dhaka, Bangladesh in March 2016. He is now studying his M.Sc in civil and environmental engineering from BUET. He is a lecturer in the Department of Civil Engineering at Presidency University, Bangladesh since May. 